\title{
Environmental Conditions for English Language Learning in Malaysia
}

\author{
Noor Saazai Mat Saad \\ Faculty of Major Language Studies, Universiti Sains Islam Malaysia, 71800 Nilai, Negeri Sembilan, \\ nmatsaad@gmail.com \\ Melor Md Yunus \\ Faculty of Education, Universiti Kebangsaan Malaysia, 43600 Bangi, Selangor
}

\begin{abstract}
The importance of environment in students' language learning process should not be undervalued. This research, underpinned by the Sociocultural Theory by Vygotsky that centres on the tenet of mediation, looks at how the environmental conditions assist and hamper the English learning of a group of international students. The research questions that guide this study are (1) What are the elements in the environment that assist/hamper the English language learning of international students learning English in an institution in Malaysia? (2) How do the conditions in one of these elements assist and hamper the English language learning of international students learning English in an institution in Malaysia? The participants for this study were nine international students studying English in an institution in Malaysia. Data were gathered through observations, interviews and document analysis. Data were analysed thematically and managed by ATLAS.ti. The data revealed that firstly, there were three themes emerging from the data - situations, people, and things/media. Secondly, further deliberation presents two sides of a coin to the 'situations' - where on one side, there are, for example, situations that promote English, while on the other side, there are situations which do not. All in all, the findings further enhanced the importance of conducive environment to promote learning.
\end{abstract}

Keywords: English language learning, international students, Malaysia, mixed-setting language environment, sociocultural theory

\section{Introduction}

Deliberations on learning environment usually debate on dichotomy of the nature of the environment. The examples are natural -- classroom learning (Spolsky, 1989), spontaneous (untutored) -- guided (tutored) language learning (Klein, 1986), and instructed - uninstructed (as cited in Spolsky 1989).

Spolsky (1989) lists 74 conditions that should be met in enabling second language learning. These conditions are coalesced into a proposed general theory of second language learning. The importance of learning environment is acknowledged in the list with 10 conditions dedicated to either natural or classroom learning. Natural learning provides an environment "surrounded by fluent speakers of the target language", it is a "real outside world, open and stimulating", with "language that is free and normal", and "the attention is on the meaning of the communication" (Spolsky, 1989, p. 171). Classroom learning is undoubtedly opposite of the descriptions for natural learning.

Klein (1986) distinguishes spontaneous (untutored) and guided (tutored). The former denotes learning through daily communication in a natural setting. This further suggests that the focus is on the communicative language and little attention on the correct language. This could have backfired but drawing the attention to 'communication/communicative', Klein (1986, p.17) writes "being concerned with effective communication rather than 'proper language', the spontaneous learner takes a different attitude to the means of verbal communication than is customary in a language teaching setting". In other words, their affective state might be very positive in using the language to pass the message across. On the other hand, guided (tutored) is attached to among others, "learning that is open to systematic and intentional influence" (1986, p.18), that is to say English language classroom. Thus, in spelling out learning environment, it can be surmised that learning environment embodies the people in it, the things or the artefacts found in it, and the activities that take place in the environment. 
Learning and the environment for learning in this research are underpinned by Sociocultural Theory (SCT) by Vygotsky. SCT propounds mediation in language learning (Mamour, 2008; Lantolf, 2000) which delineates that there are elements in the environment that help learners to expedite their language learning.

Bringing this deliberation to the issue of Language Learning Strategies, there is a vast difference in the strategies used. In class, learners can strategise to sit near the teacher, to ask question, to take down notes and many more. There are undoubtedly overlaps between the two environments but since this research deals with strategies employed out of the classroom environment, it leans its core on natural learning (Spolsky, 1989) or informal context (Ellis, 1994). However, not all of the characteristics discuss above are reflected at the actual research site. The obvious one is regarding natural environment having fluent speakers of the target language. This is unlike the nature of the natural learning environment in this research as the research site does not provide an environment full with fluent English speakers, instead it is a mixedsetting language environment.

\section{Main Issue}

Although it has been 'said' in literature on English in Malaysia that English is a second language (ESL) in Malaysia (Thirusanku \& Melor 2011, p.2); other examples are Foo \& Richards, 2004; Murugesan, 2003), the reality is not very straightforward such that not everyone is able to converse in English and not every place is English-friendly. English is learnt and used instrumentally (Lee Su Kim et al. 2010, Mohamed Amin 2000) for example to excel in exams and land a good-paying job. Thus, the natural environment in Malaysia provides conditions that may assist or otherwise, hamper the English language learning.

\section{Aim and Research Questions}

This paper aims to delineate the conditions in the environment for the English language learning of a group of international students studying English in an institution in Malaysia. In achieving the aim, two research questions are generated:

1. What are the elements in the environment that assist/hamper the English language learning of international students learning English in an institution in Malaysia?

2. How do the conditions in one of these elements assist and hamper the English language learning of international students learning English in an institution in Malaysia?

\section{Methodology}

Based on the nature of the research questions, this research is under the qualitative paradigm where the methods of data collection include document analysis, observation and interview. The documents involved are the online postings submitted by the participants and photos taken by them around the places that they like to frequent. For 10 weeks, the participants posted a weekly reflection on their English language learning experiences and a response to a topic on Google+ stream. On the other hand, the observations were done on the activities run by the institution which involved the international students. As for the interview, it consists of two rounds of face-to-face or email interviews with them - at the beginning and at the end of the semester. The data were analysed thematically and managed by ATLAS.ti version 7.

The participants comprise nine international students who were undergoing an English Language Proficiency Class (EPC) as to fulfil the language requirement set by the institution. Six of them were males while three were females. Five were doing their doctorate studies whereas the others were pursuing their master's degrees. Almost all of them were from the Middle Eastern region while one was from Indonesia. All of them, except an Iranian, could speak Arabic. They are addressed using pseudonyms in this paper.

\section{Research Site}


The institution where the participants were studying is one of the five research universities in Malaysia. The main language for teaching instructions for undergraduate classes is Bahasa Malaysia while for postgraduate classes, the medium of instruction 'varies depending on the programmes' (General frequently asked questions www.ukm.my/isc). Further, lecturers are encouraged to use English when the student population in the class includes international students. The institution hosts 2,333 (data of new postgraduate students in 2010 from www.ukm.my/pps) postgraduate international students from various countries. All international students are required to have IELTS Band 6 or TOEFL 550 to enrol. If they do not fulfil the requirement or do not reach the stipulated score, they have to go for an English placement test. If they only manage to get Bands 1 or 2 from the 6 bands, it is necessary for them to go for English Proficiency Class (EPC). Besides that, all international students are required to undergo Bahasa Malaysia class for two semesters.

\section{Findings and Discussion}

The findings are reported according to the research questions. The extracts from the online postings and interviews are in italics. For the interview extracts, the interviewer's parts are in bold. Each extract is followed by the pseudonym and the type of data, for example (Fatinmalik, op_top3). It means that the extract is from Fatinmalik (pseudonym) and taken from her online posting for topic number 3. Others are 'op_ref' for online posting for weekly reflection, 'int_2' for the second interview, and 'obs' for observation. Each research question is followed by a discussion on one aspect of the prominent findings.

\section{Research Question 1 - What are the elements in the environment that assist/hamper the English language learning of international students learning English in an institution in Malaysia?}

The data revealed that there are three elements that provide the conditions in the environment that assist/hamper the English language learning of these students. They are the situations, people and things/media as seen in Figure 1.

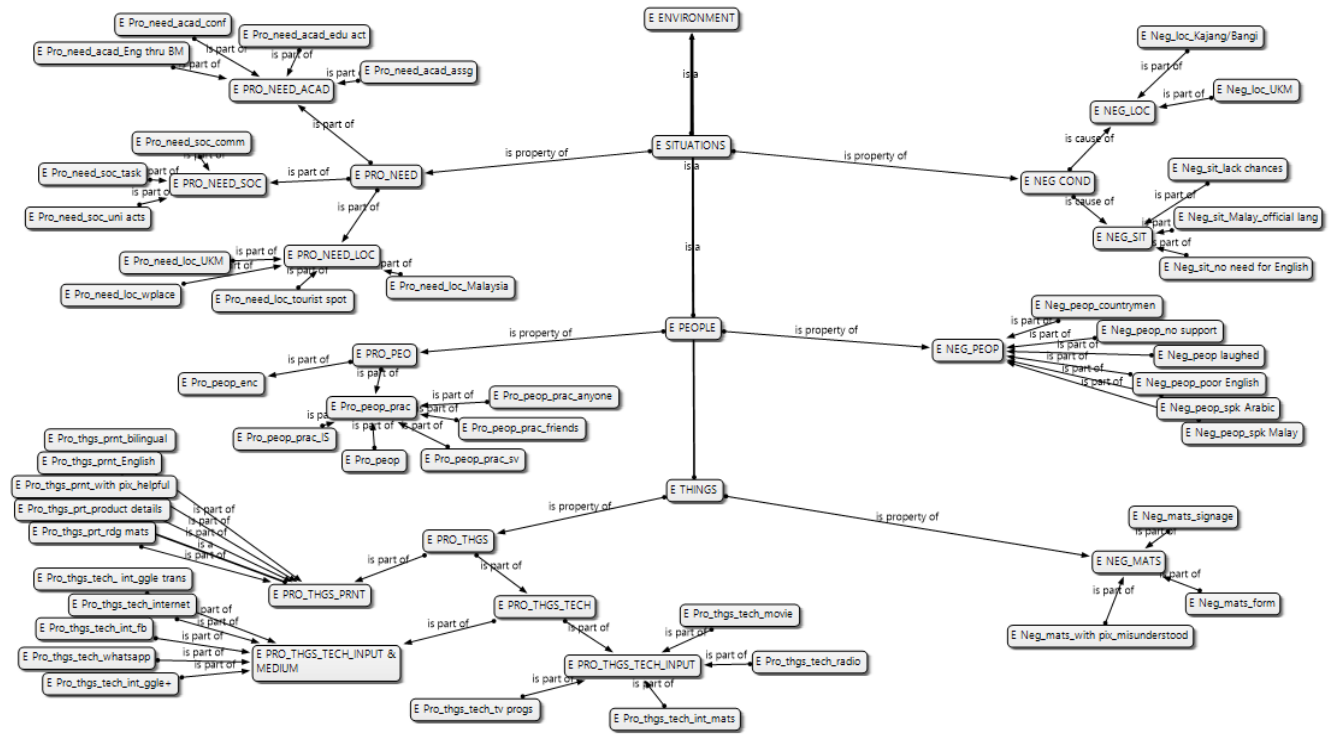

Figure 1: Elements in the environment for English language learning - A network view from ATLAS.ti

Figure 1 is an output from ATLAS.ti. It is a network view which gives a visualisation of the themes discovered from the collected data. There are three main themes with the positive and negative conditions. Each condition has a few subthemes. Further, there are also sub-subthemes which give more details to the findings.

The first theme is the situations. The participants reported that they experienced situations where they needed to use English and also situations where English was not needed. English was used in social and academic activities where they 
communicated with other students - local and international; during activities at the institutions, and educational activities like conferences in and out of the institution. Furthermore, being in Malaysia - a foreign country for these international students, and especially in tourist spots like Kuala Lumpur and Langkawi; required them to use the English language.

The second theme or the element that assists/hampers these international students' English language learning is the people around them. They reported of people who encouraged them to be better at using the language. People like their family members, supervisors, and friends also indirectly encouraged them by becoming the people whom they could practise speaking the language with. On the other hand, their own countrymen have become the element that hampers their advancement in English language learning. This is because when there were gatherings of people from the same country or those who share the same mother-tongue, all would not be using the English language, instead they would be speaking the language that they were comfortable in. Moreover, there were also incidents where they met locals or other nationalities who were interested to learn and practise Arabic language. So, they used Arabic with these people.

The data revealed that the third element which assists/hampers the English language learning of the international students is the things or media around the institution, the participants' residential areas and also places that they frequent. They reported that printed materials and technological gadgets around them have boosted their English language learning. The technological gadgets can be divided further into two categories - passive and active media. The former which refers to one-way interaction media includes television and radio programmes, movies and articles on the internet. Whereas the latter comprises Facebook (Fb), Google+, Whatsapp and Google Translate. Thus, active media refers to two-way interactions where the users get feedback, for example via $\mathrm{Fb}$ on the internet and Whatsapp on smartphones. They used these media to interact with people in English.

All in all, there are more conditions that assist English language learning among international students than conditions that hamper them from doing so. In fact, based on all the extracts under all the three themes, there are triple reported cases of positive environmental conditions compared to the negative conditions. 390 reported cases for positive environmental conditions and only 93 for its opponent as seen in the output from ATLAS.ti (Appendix).

\section{Discussion for RQ 1}

The answers for RQ1 are the three elements - situations, people and things/media which assist/hamper the English language learning of international students studying English in a Malaysian institute. Two of the themes manifest the tenet of mediation from the Sociocultural Theory (SCT) by Vygotsky (1978). Lantolf (2000) spells out mediation to cover symbolic and physical tools. The former refers to language, arts, music and numbers, whereas the latter can be anything including hammer. He also adds that 'someone else and cultural artefacts' (p.17) as mediators. With the regards to the findings of this research, the international students reported engaging people like their supervisors, other international students, or even anyone to have a conversation with. Furthermore, these participants described how they have utilised the things/media around them. They used television, radio, smartphone and internet to learn and practise English. Hence, the people and the things/media have become the mediators between the participants and the end result - that is to practise the English language.

\section{Research Question 2 - How do the conditions in one of these elements assist and hamper the English language learning of international students learning English in an institution in Malaysia?}

In tackling the second research question, one of the three themes will be discussed in detail. Among the three themes or elements found to assist/hamper the English language learning of the participants, the first theme is most appropriate. This is in tandem with the earlier mentioned main issue which highlights that Malaysia has a mixed-setting environment in terms of the use of English language in the environment. Table 1 below displays the subthemes and sub-subthemes for 'situations'.

Table 1: Subthemes and sub-subthemes for 'situations' that assist and hamper English language learning

Environmental conditions that assist and hamper English language learning

\begin{tabular}{l|l} 
Theme & Theme 1- Situations
\end{tabular} 


\begin{tabular}{|c|c|c|c|c|c|}
\hline & \multicolumn{3}{|l|}{ Assisting - Need English } & \multicolumn{2}{|c|}{ Hampering - Negative situations } \\
\hline $\begin{array}{l}\text { Subthemes } \\
\text { Sub-subthemes }\end{array}$ & $\begin{array}{l}\text { Social } \\
\text { communicate, perform } \\
\text { social tasks, be involved } \\
\text { in activities at the } \\
\text { institution }\end{array}$ & $\begin{array}{l}\text { Academic } \\
\text { attend academic } \\
\text { conference, } \\
\text { participate in } \\
\text { educational } \\
\text { activities, } \\
\text { complete } \\
\text { assignments, } \\
\text { learn English } \\
\text { through BM }\end{array}$ & $\begin{array}{l}\text { Locations } \\
\text { Malaysia, the } \\
\text { institution, } \\
\text { tourist spots, } \\
\text { workplace }\end{array}$ & $\begin{array}{l}\underline{\text { Unhelpful }} \\
\text { conditions } \\
\text { lack chances, } \\
\text { no need for } \\
\text { English, Malay } \\
\text { is the official } \\
\text { language }\end{array}$ & $\begin{array}{l}\frac{\text { 'UnEnglish' }}{\text { locations }} \\
\text { Kajang/Bangi, the } \\
\text { institution }\end{array}$ \\
\hline
\end{tabular}

Table 1 clearly displays the delineation of the conditions that assist and hamper English language learning under the first theme. Situations can be seen as two sides of a coin - environmental conditions that assist and those that hamper English language learning. Under each, there are a few subthemes. Situations that boost English language learning include social, academic and being in certain locations. On the other hand, negative situations include conditions that are unhelpful and locations where English was not used thoroughly due to reasons to be discussed under the sub-subthemes. The discussion that follows begins with the elucidation of what 'situations' refer to, then, the situations that assist English language learning. Next is the discussion of the other side of the coin; the situations that hamper English language learning before it ends with a discussion.

\section{Situations}

\section{Need English}

\section{Negative situations}

Being sojourners, these participants face new and different situations every day. When they go about doing their daily routine as students as well as parents/social beings; they go to town, institution and travel around the country. There were situations when they perceived there was a need to use English like to socialise and to be involved in academic activities. Further, they reported that being in certain locations also required them to use English. These situations boosted their English language learning (ELL). On the contrary, there were also situations and places that hampered their English language learning due to certain constraints like lack of chances, there was no need for English as well as during activities where Malay was the official language.

\section{Assisting ELL - Need English}

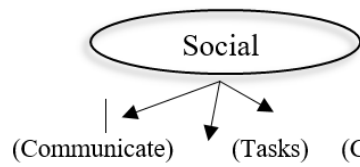

(Activities at the institution)

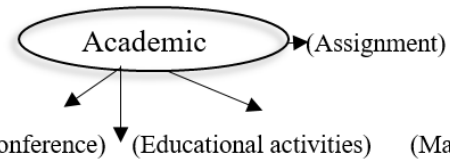

(Learn English through BM)

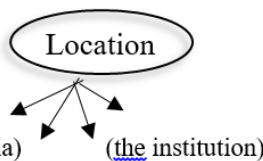

(Tourist Spot) (Workplace)

The data revealed three situations that required the participants to use English. The notion of 'using English' here includes the participants speaking in English, listening, reading and even writing in English. The situations are during socialisation, academic endeavours, and also in certain locations. The discussion in this section follows the order of the mentioned situations.

The first situation concerns the socialisation of the participants. There are three situations which are related to socialisation - situations that require them to communicate, complete tasks and participate in university activities. The participants had to communicate in order to go through their daily routines. Basri, Imran, Faizal, Fatinmalik, Mohsin, and Nabil shared the routines they had to do that needed English as the medium of communication. Specifically, they used English when they 
"went to the market... and to the hospital for treatment" (Basri, op_ref2), went "to the shops" (Imran, op_ref2), "[spoke] English" to international friends (Mohsin, op_ref5), and when they went out "to eat, ...to take taxi or ask how [to] go to the any place" (Faizal, int_1).

Besides everyday activities, in socialising, participants were involved in accomplishing tasks; more precisely non-academic tasks like Nabil reported that "[he needed to use English in settling his problem with the ATM card and filing a report to the police about his friend's stolen laptop]" (Nabil, op_ref5). Another task that was prevalent was observed in an activity at the institution involving international students. The task involved giving instructions and the activity was the $4^{\text {th }}$ International Food Festival run by General Studies Centre (GSC) and International Student Centre (ISC). It was actually an activity for international students who were undergoing Bahasa Melayu class at GSC. Thus, the language used was Bahasa Melayu. However, it was noticed that when it came to the task of giving instructions to all students, it was done in English. Below are the instructions extracted from the field notes on the observation done on 13 December 2012:

\section{Extract 1: After announcing the arrival of the dignitaries - the emcee speaks a line of English - "PLEASE STAND UP"}

\section{Extract 2: The emcees actually announce "ALL BOOTHS SHOULD SERVE THE BEST FOOD TO THE VIPs".}

Extract 3: $11.30 \mathrm{am}$. Emcees instruct the students who are in front of the stage to leave the place because there is going to be another performance, also by Malaysians. When the announcement is ignored, the emcees repeat the instruction. This time in English - "PLEASE LEAVE THIS STAGE AREA. WE ARE GOING TO DO A PERFORMANCE".

\section{Extract 4: Around $1.15 \mathrm{pm}$. Once again there is an announcement made in English "PLEASE CLEAR THIS AREA".} (Obs_13 Dec 2012)

All of the data extracts above show the instructions (in capital letters) given in English although the activity was supposed to encourage the use of Bahasa Melayu. Undeniably Bahasa Melayu was utilised in the welcoming speeches and other parts, but when it was time to instruct the students to do something like to stand up and clear the area, the announcement had to be made in English. As observed and noted in extract 3, the emcees had to repeat the instruction in English which was initially made in Bahasa Melayu. Hence, interestingly the task of giving instructions to ensure the smooth sailing of a programme had to be done in English as the participants of that programme were mostly international students.

The discussion above leads to the next and last situation that requires participants to use English to socialise. The situation is during the participants' involvement in the activities at the institution. There were two observed activities conducted at the institution - the $4^{\text {th }}$ International Food Festival which was partly discussed in the preceding paragraph, and the International Culture Night. Both were organised partly by the ISC and were conducted on 13 and 18 December 2012, respectively. As discussed in the previous paragraph, English was used prevalently during the food festival. Participants like Imran, Basri, Faizal and Fatinmalik reported the use of English during the activity. Imran shared how "[the international students had to collaborate in making the activity successful]" (Imran, op_ref8) and therefore he "tried to speak in English" (Imran, int_2) during the activity. Faizal and Fatinmalik were more specific in their recounts of their participation in the food festival. Faizal talked about the guest of honour who went around the booths to taste the food. He said "he had to use English" (Faizal int_2) in his interaction with the students manning the booth in order to ask about the ingredients of the food and other related matters. Fatinmalik referred to the same issue - the interaction about food, but her focus was on the other students at the festival. She remarked, "all talking English and when they come to see the food I think all English" (Fatinmalik, int_2) because the booths were from various countries represented by the international students in the institution and the students or the visitors were of different nationalities. The issue of prevalent English usage also resonates in the field notes of the observation done on the activity:

I can hear through the noise the conversation between Ir Dr Othman and the students who are manning the booth. Ir Dr Othman's questions are mainly about the name of the dish, the ingredients, and other general questions. He of course uses English but with some BM words. The students do the same.

(Obs_13 Dec 2012)

All of the participants of this study except for Basri were present during the food festival. Some like Fatinmalik, Shamsulwahab and Faizah were involved actively in preparing and serving the food to the students or visitors to their booths. Although Basri was not present during the activity, he supported activities like the food festival because to him it was also about learning English but it was done in a more fun manner. This is evinced in the exchanges below:

the activities, students get many benefits because they need to talk so we need when he join means he will share and 
when he share he will communicate so he needs to use the language and the activities... The activities more better than classes [because] activities no need to sit and listen, it is like enjoy

\section{And learn}

And refresh and they didn't feel that like he learn English. It is like activity normal yes

(Basri, int_2)

In fact, Imran suggested other activities like trips and he even advised students to take part in the activities. He wrote, "I advise students to...participate in various activities" (Imran, int_2).

Besides English being needed as a medium for participants to socialise in their daily interactions and social activities at the institution, it is also used for academic endeavours. This is in line with the discussion of academic tasks accomplished. One of the tasks includes participating in conference as shared by Fatinmalik (op_ref, int_2) and Shamsulwahab (int_2). There are another three situations in the participants' academic endeavours that require them to use English - participating in educational activities, doing their assignments and learning English through Bahasa Melayu.

The educational activities here refer mainly to the participants' involvement in their own course of study. Those who are doing their master's degree like Mohsin, Faizal, Nabil, and Fairus talked about having to read their coursework materials, and listen to lectures which are in English. Mohsin quipped, "This week I should read 1200 slides for The control project IT course!! :0" in his reflections and added that he hoped to "learn some new words" (Mohsin, op_ref3). Fairus then talked about "the lecture changed for me from Arabic lecture to English lecture" (Fairus, int_1). Furthermore, Faizal and Nabil mentioned that being in a group that consisted of students from different nationalities had allowed them to converse in English while discussing and solving problems. Faizal said, "in groups with Malaysian students and another country so we must talk [English]" (Faizal, int_2).

As for the participants doing their doctorate degrees, their concerns revolved around thesis and interactions with their supervisors. Fatinmalik reported using English with her supervisor (Fatinmalik, int_1) while Shamsulwahab said that "we write thesis in English. Should we write in very good method. Academic writing" (Shamsulwahab, int_1). Thus, it is axiomatic that these situations make participants learn English.

It has been specified that educational activities are about the participants' own course of study. However, the next situation is about the assignments that are related to EPC - the English language proficiency class that they were doing when this research was conducted. The assignment that has provided an excellent avenue for the participants to use and in fact improve their command of English in writing is through online postings activity. All of the participants labelled online postings activity as positive. While Fairus, Fatinmalik and Mohsin rated this as only "good" (Fairus, op_top10; Fatinmalik, op_top10; Mohsin, op_top10); Basri saw this as "a major shift" in his writing experience because writing used to be "a nightmare" for him but doing it for every week on different topics for about 10 weeks has made writing "became easy for us"(Basri, op_top10). In fact, Basri and Fairus praised this activity in their reflections, topic 10 on online posting and also interview 2. However, among the many responses towards online postings activity, Mohsin's statement has given a deeper insight into effective ways for students to learn English. He expressed, "I felt relaxed when I write my posts and I didn't have this feeling when I was in the classes" (Mohsin, op_top10). This suggests that providing a stress free environment might encourage learning.

The next and last situation under the subtheme of academic endeavours is 'learning English through Bahasa Melayu'. It is a requirement for postgraduate international students in the institution to attend Bahasa Melayu classes for two semesters. Therefore, at the time of the research, all except Basri were going through the Bahasa Melayu class. Although it was a Bahasa Melayu class; English was inevitably used. This is as expressed by Fatinmalik in the exchanges below;

In Bahasa when you learn, at the same time you learn English

\section{Really? How?}

Because some words when the teacher tell us, we don't know what's the meaning in English. So I go translate this word into English and Bahasa. So I learn English and Bahasa in Bahasa class. (laughs)

(Fatinmalik, int_1) 
Mohsin, similar to Fatinmalik's reaction above, laughingly admitted learning English in his Bahasa Melayu class. This is seen in the following data extract:

\title{
You use BM [Bahasa Melayu] all the time in class?
}

No! English. Sometimes we use BM for reading or presentation.

\section{But to explain the lecturer use...}

English, yes.

\section{So you are learning English also in Bahasa Melayu class}

(laughs)..for me... (Mohsin, int_1)

Instead of just in their Bahasa Melayu class, Fairus also experienced learning English through Bahasa Melayu in casual interactions on the bus. She relayed;

for example when I in the bus, most of my time I always ask them to learn me about Bahasa.

\section{I see}

But they explain in English. I understand them when they speak English

\section{You learn Bahasa through English?}

\author{
Yeah \\ (Fairus, int_2)
}

The first two types of environment that promote the use of English have been discussed. The environment that needed English to be used for socialisation was first to be discussed and it was followed by environment that required English for academic endeavours. The third is the type of location that promotes the use of English. There are some locations that were reported to have conducive surroundings to boost the use of English. The data revealed four locations - Malaysia, the institution, tourist spots and workplace.

Coming from countries where English is not prevalently used, these participants made comparison between the use of English in their home countries and in Malaysia. Definitely they would find more and better English usage here, in Malaysia. Fairus, Fatinmalik, Nabil, Shamsulwahab and Basri openly announced this. Shamsulwahab said, "before coming to Malaysia, I don't speak in English" (Shamsulwahab, int_1). Fatinmalik also made a comparison when she uttered "I think here is better than my country. Why? Because here you can speak with teacher all English" (Fatinmalik, int_1). Along the same line, Basri observed that other international students "use English when they arrive to Malaysia" (Basri, op_top4). The reason for this is that the participants seek opportunities to speak English and they could easily do so in certain areas.

The participants were more specific when they named places in the institution as conducive for using English. Fatinmalik chose the library as she could strike conversation with people there (Fatinmalik, int_2). Nabil said Za'ba - a residential college in the institution (Nabil, int_1) as a place to practise his English. He then reiterated this in interview 2. Unlike Nabil, Faizal had a different perception of English usage in Za'ba. He said "like Za'ba, no. Pusanika, yes" when asked where he could use English more freely at the institution.

The data revealed the third location where English is commonly used - the tourist spots. Only Faizal discussed this in great length as he mentioned in both interviews 1 and 2. He talked about having no communication difficulty in $\mathrm{KL}$, "I go to $\mathrm{KL}$ like tourist. They know English. When they talk, I understand." (Faizal, int_1). In interview 2, there were three mentions on this. In line 303, Faizal again talked about KL, "But you go to KL, you talk to anybody, in the street, they talk to you because like tourist city". Further, he pinpointed specific places in KL (line 457) where he could comfortably speak English - KTM (Keretapi Tanah Melayu), KL Central, KFC (Kentucky Fried Chicken), and McDonald's. The former two are the stations for public transportations whereas the latter two are famous franchise fast food restaurants. The last bit about using English at tourist spots is in line 685 where he mentioned talking to other tourists in Langkawi (Faizal, int_2).

The last location that requires English is the workplace. Among the participants, Basri was the one who worked during the course of the research. He worked as an Arabic teacher at International School Malaysia (ISM), Gombak. Before that, he was working as an Arabic teacher too at Qiblah school in Bangi. He said, "in IS[M] everyone talking in English, foreigners, 
students..." (Basri, int_1). The environment that everybody converses in English became the impetus for him to enhance his command of the language. He echoed this again later: "With teachers I need to speak in English, with students, office, the meeting" (Basri, int_2).

Similar to the earlier location - tourist spots which was only mentioned by Faizal; this location - workplace, was also only experienced by Basri. However, Basri provided a set of evidence of photos that he snapped around the school compound - they are the photos of announcements, reminders, articles, and notices, and they are all in English (pho_Basri). Basri voiced out that being in such an environment was really conducive for his English learning. He said,

it is good one for me because you know IS school is an international school. You have office like small country and I spend almost all my time there from I went from I go to school $7 \mathrm{am}$ I come back to 5 sometimes they have meeting $6 \mathrm{pm}$ so it is almost, ok, it is like small country for me. Office, staff room, assembly area, and everything in English. Like a closed world for you. (Basri, int_1)

Actually, Basri was the lucky one to get a chance to be 'in a small country' where English is widely used. This is because, when a scenario of being given a sum of 1 million USD to be used to improve their English for topic 8 for the online posting on Google+, majority of the participants chose to spend time in English-speaking countries (Faizal, op_top8; Basri, op_top8; Fairus, op_top8; Imran, op_top8, Mohsin, op_top8; Nabil, op_top8; Shamsulwahab, op_top8). The countries of their choice were the UK, the US, and Canada.

All in all, the needs to socialise, perform in academic endeavours and be in the right location are situations that assist or promote the use of English. However, there is always the other side of the coin where there are situations that do not really help these participants to even use English. This is discussed in the next section.

\section{Hampering ELL - Negative situations}

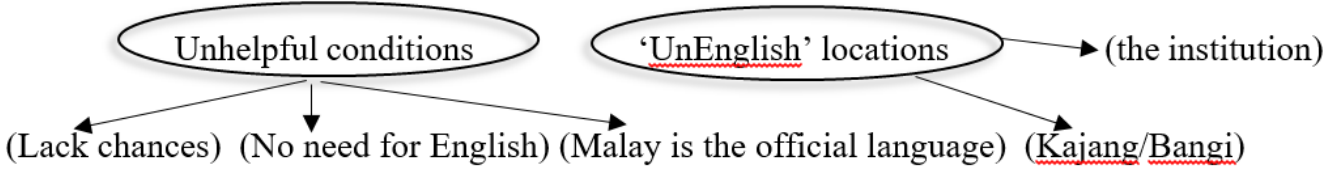

In contrast to the above, this section focuses on the situations that hamper the English language learning (ELL) of the international students in this research. There are two subthemes to be discussed. One is the unhelpful conditions and the other is the 'unEnglish' locations.

The participants shared three unhelpful conditions that deterred them from using or practising and thus learning English. The situations are lack of chances, no need for English, and also when Malay is the official language. Firstly, participants complained about lack of chances to practise English mainly because of time. They used up their time to carry out their 'own responsibilities' and be involved in their 'own course'. These activities left them with 'no time'. As for the subtheme of 'no need for English', it was observed that very little English was used during the International Cultural Night. An extract from the observation of the event is as follows:

A note on the English usage - out of the two hours, only about 7 minutes of English (as recorded). It is mainly for announcements made by the emcees. No speech is made by any of the guests.

(Obs_18 Dec 2012)

Somehow, the minimal use of English was unavoidable due to the nature of the event. The purpose of the event was to introduce the culture of one's country. Hence this included presenting folk songs, performing traditional dances and for authenticity, national language was used. Therefore, English was used only to introduce the countries and read out the itinerary of performances. Thus, it was unsurprising that in the two-hour international event, there was only seven minutes of English used.

The last subtheme which is 'Malay is the official language' collects the mentions of Malay being the national language in an event and in the institution and also Malaysia. Mohsin and Faizah rationalised that the use of more Bahasa Melayu (Malay) in the environment of the institution was due to "[the institution] is national university" (Mohsin, int_1) and thus 
"encourages the use of Bahasa Melayu" (Faizah, int_2). Moreover, since the event of the $4^{\text {th }}$ International Food Festival was organised jointly by ISC and GSC Bahasa Melayu class, Bahasa Melayu or Malay was the official language. This is evinced in the field notes from the observation. The emcees spoke Malay, the speeches by distinguished guest and the director of the event were in Malay, the tags for the hampers were in Malay and even though the students were observed to use more English, they "want[ed] to show off their command of Bahasa Melayu] (Obs_13 Dec 2012), so they spoke Malay whenever they could.

The other negative condition that impedes the English language learning of these participants is the location that they found less conducive to use English - thus termed as 'unEnglish' locations. The locations are Kajang/Bangi and the institution itself. Among the participants, Basri and Nabil had a lot to say about this, mainly because they both had been to two different places and thus were able to make comparison. Basri was first teaching in and staying around Qiblah school, Bangi before he moved to Gombak to teach at the International School Malaysia there. Nabil, on the other hand, stayed on campus in Za'ba before moving out to Kajang. Basri said there was no need for English because he taught in "the school is full Malaysians" and shopped at the "small shop...[where]everyone is Indonesian" (Basri, int_1). As for Nabil, he noticed that his use of English was deteriorating since he moved out from Za'ba to Kajang. He expressed, "I have moved to Kajang...in fact my use of the English language less [than] the former because of the community does not speak English" (Nabil, int_2).

The next location is the institution. Some participants like Nabil and Fatinmalik reported that they thought the institution to be a place for them to practise English, this is as seen in the earlier discussion on the location that requires them to use English. However, there are participants who thought otherwise. Among them, Faizal opined that the institution, especially Za'ba was a location that did not inspire him to use English. He compared buying food in Za'ba to going to a restaurant in Nilai (a town with lots of international students). This is seen in the exchanges below:

Even the Indian restaurant...the worker know basic English. Like I want something he would understand, I go to shop, he understand me, the security,

\section{Understand you too}

Yeah yeah. If you want to compare here, if I go to Za'aba, they don't understand

(Faizal, int_2)

Faizal justified that the situation was such because there are many international students in Nilai whereas in the institution that all of them are currently studying, the majority of the students are Malaysians. Faizal further compared Za'ba to some places in KL like KTM, KL Central, KFC and McDonald's and he also compared Za'ba to other places in the institution. He said, "Za'ba no. Pusanika, yes [because] it's centre for students. Everything, library, restaurants, banks, shops" (Faizal, int_2).

All in all, it can be surmised that since Malay is the official language of the event, and of the institution, there were times when the participants were deprived of using English.

\section{Discussion for RQ2}

The 'situations' in this discussion reflect a few of the 74 conditions expounded by Spolsky (1989). Condition 7 highlights the association between learning English and developing academic language skills. This is evident in the subtheme of academic situations where the participants reported using English during their involvement in conferences, and other educational activities. Conditions 15 and 63 emphasise that learning a second language is associated with communication. The former aims to achieve control of a language for communicative purposes while the latter shows that a second language is chosen and used for communication in a social context. This can be seen in the subthemes of social conditions that make the participants practise the English language.

Looking at the activities reported by the participants, it can be deduced that they were seeking opportunities to practise using the English language and in many ways, the conditions in the environment allow for this to take place. Thus, mapping this onto Spolsky's (1989) list of conditions for second language learning, it matches conditions 62 and 64 . Condition 62 is 
about how opportunities to use the language can lead to fluency. Along the same line, condition 64 highlights that using the language is equivalent to learning the language.

At an angle, it can be seen rather obvious that the situation or the environment has the power to dictate human behaviour. When the environment allows, the participants are able to practise English like Basri who worked at International School Malaysia. The school provided the English-speaking ambiance for him thus he took the opportunity to practise speaking in English with students, parents, and colleagues.

However, looking from another angle, there is also evidence of how the people influence the environment. In the case of 'learning English in Malay (Bahasa Melayu) class'; the environment was supposedly imbued with Malay language as it was a Malay lesson but since there was a need for the students to understand, to interact and to learn; and for the lecturer to make the students understand, to interact and to teach, the environment/situation was changed - English was used instead.

\section{Summary and conclusion}

The aim of RQ1 was to identify the environmental conditions that assist/hamper English language learning (ELL). The data revealed three environmental conditions that both assist and hamper ELL - situations, people and things/media. The subthemes and sub-subthemes in Table 1 show the evidence. The table seems to be lopsided, favouring the conditions that assist English language learning. It does not only show that there are variety of positive conditions, but there are also more reports on positive encounters in the environment as compared to negative. This is as proven by the 390 extracts for positive environmental conditions as compared to 93 discouraging environmental conditions (Appendix). Hence, it can be surmised that the environmental conditions in Malaysia encourage ELL.

RQ2 gives further elucidation of the environmental conditions by discussing the first theme in detail. 'Situations' are twosided as reported by the participants. Both delineate clear positive and negative aspects of the situations. The former is suitable to assist the participants in their language learning while the latter is not, in fact, it might cause inconvenience. The main reason for these different situations is the mixed-setting language environment that Malaysia has.

All in all, although Malaysia provides a mixed-setting language environment, the evidence of the triple amount of extracts for positive environmental conditions as compared to the negative environmental conditions suggests that the institution in particular and Malaysia in general provide a conducive environment for English language learning.

\section{References}

[1] Ellis, Rod. (1994). The Study of Second Language Acquisition. Oxford: Oxford University Press.

[2] Foo, Bernadette, \& Richards, Cynthia. (2004). English in Malaysia. RELC Journal, 35(2), 229-240.

[3] Generally FAQs. (2011). International Students in UKM. Retrieved 12 May, 2012, from http://www.ukm.edu.my/

[4] Klein, Wolfgang. (1986). Second Language Acquisition. Cambridge: Press Syndicate of the University of Cambridge.

[5] Lantolf, James P. (2000). Introducing Sociocultural Theory Sociocultural Theory and Second Language Learning (pp. 1-26). Oxford: Oxford University Press.

[6] Lee, Su Kim, Lee, King Siong, Wong, Fook Fei, \& Azizah, Ya'acob. (2010). The English language and its impact on identities of multilingual Malaysian undergraduates. GEMA Online ${ }^{\mathrm{TM}}$ Journal of Language Studies, 10(1), 87-102.

[7] Mamour, Choul Turuk. (2008). The relevance and implications of Vygotsky's sociocultural theory in the second language classroom. ARECLS, 5, 244-262.

[8] Mohamed Amin Embi. (2000). Language learning strategies: A Malaysian context. Bangi: Fakulti Pendidikan.

[9] Murugesan, Vinodini. (2003). Malaysia promotes excellence in English. ESL Magazine, 26-28.

[10] Spolsky, Bernard. (1989). Conditions for Second Language Learning. Oxford: Oxford University Press.

[11] Statistics of International Students in UKM.). 2012, from http://www.ukm.my/pps 
[12] Thirusanku, Jantmary, \& Yunus, Melor Md. (2012). The Many Faces of Malaysian English. ISRN Education, 2012, 114. doi: $10.5402 / 2012 / 138928$

[13] Vygotsky, Lev. (1978). Interaction Between Learning and Development Mind and Society (pp. 79-91). Cambridge: Harvard University Press.

\section{Appendix}

\section{ENVIRONMENTAL CONDITIONS}

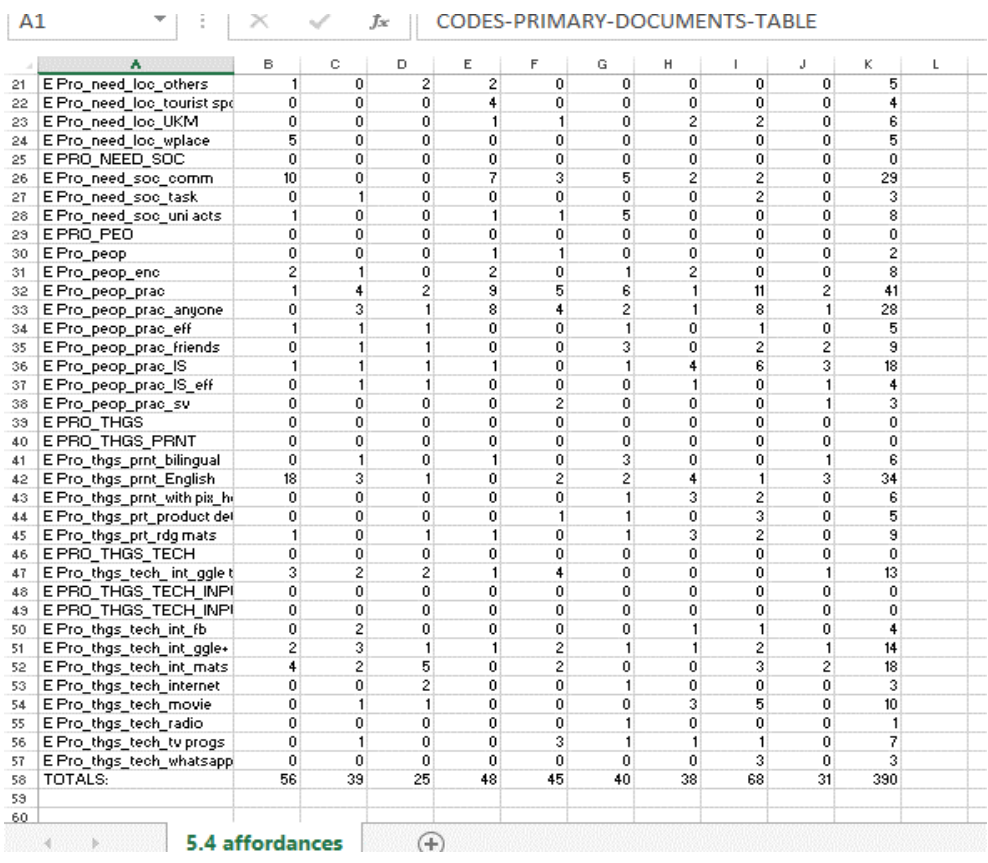

Environmental conditions that promote English language learning reported - 390 cases

\begin{tabular}{|c|c|c|c|c|c|c|c|c|c|c|}
\hline & SS BASRI_ & Is FAIRUS. & SS FAIZAH. & SS FAIZAL & SS FATINN & SS IMRAN & s5 MOHSI & SS NABIL_I & I SS SAMSU & TOTALS: \\
\hline E Neg_attitude & 1 & 0 & 0 & 0 & 0 & 0 & 0 & 0 & 0 & 1 \\
\hline E NEG_LOC & o & 0 & 0 & 0 & 0 & 0 & 0 & 0 & o & 0 \\
\hline E Neg_loc_Kajang/Bangi & 3 & 0 & 0 & 1 & 0 & 0 & 0 & 2 & 0 & 6 \\
\hline E Neg_loc_UKM & 1 & 0 & 1 & 6 & 0 & 0 & 1 & 0 & 0 & 9 \\
\hline E NEG_MATS & o & 0 & 0 & 0 & o & 0 & 0 & 0 & 0 & 0 \\
\hline E Neg_mats_form & o & o & 0 & 1 & o & o & o & o & o & 1 \\
\hline E Neg_mats_signage & o & 0 & 3 & 0 & 1 & 9 & 0 & 5 & 1 & 19 \\
\hline E Neg_mats_with pix_mis & 0 & 2 & 0 & 0 & 3 & 0 & 0 & 0 & 1 & 6 \\
\hline ENEG_PEOP & 0 & 0 & 0 & 0 & 0 & 0 & 0 & 0 & 0 & 0 \\
\hline E Neg_peop laughed & o & 0 & 1 & 2 & 0 & o & o & 0 & 0 & 3 \\
\hline E Neg_peop_countrymen & 0 & 0 & 1 & 1 & 1 & 0 & 3 & 0 & 1 & 7 \\
\hline E Neg_peop_no support & 0 & 0 & 0 & 0 & 1 & 0 & 0 & 0 & 1 & 2 \\
\hline E Neg_peop_poor English & $\circ$ & 1 & 0 & 3 & 0 & 0 & 0 & 0 & 1 & 5 \\
\hline ENeg_peop_spk Arabic & o & 3 & 3 & 1 & o & o & o & o & o & 7 \\
\hline E Neg_peop_spk Malay & 2 & 2 & 1 & 3 & 1 & 1 & 0 & 0 & 0 & 10 \\
\hline E NEG_SIT & o & 0 & 0 & 0 & 0 & 0 & 0 & 0 & 0 & 0 \\
\hline E Neg_sit_lack chances & 0 & 0 & 2 & o & 0 & 1 & 0 & 0 & 0 & 3 \\
\hline ENeg_sit_Malay & 2 & 0 & 1 & 1 & 0 & 0 & 0 & 0 & 0 & 4 \\
\hline ENeg_sit_Malay_official & o & 0 & 1 & 0 & o & o & 1 & 0 & 0 & 2 \\
\hline ENeg_sit_no need for Eng & 2 & 0 & 1 & 3 & 0 & 0 & 0 & 2 & 0 & 8 \\
\hline & 11 & 8 & 15 & 22 & 7 & 11 & 5 & 9 & 5 & 93 \\
\hline
\end{tabular}

Environmental conditions that hinder English language learning reported - 93 cases 